\title{
New Readings of Lu Xun
}

critic of modernity and re-inventor of heterodoxy

\section{Sebastian Veg}

\section{OpenEdition}

\section{Journals}

Electronic version

URL: http://journals.openedition.org/chinaperspectives/6541

DOI: 10.4000/chinaperspectives.6541

ISSN: 1996-4617

\section{Publisher}

Centre d'étude français sur la Chine contemporaine

\section{Printed version}

Date of publication: 1 September 2014

Number of pages: $49-56$

ISSN: 2070-3449

Electronic reference

Sebastian Veg, « New Readings of Lu Xun », China Perspectives [Online], 2014/3 | 2014, Online since 01 January 2017, connection on 23 September 2020. URL : http://journals.openedition.org/ chinaperspectives/6541; DOI : https://doi.org/10.4000/chinaperspectives.6541

(C) All rights reserved 


\title{
New Readings of Lu Xun:
}

\author{
Critic of modernity and re-inventor of heterodoxy
}

\section{SEBASTIAN VEG}

M ore than any other modern writer, Lu Xun remains at the heart of intellectual discussions in China today. There are several reasons for this. One is that no sooner had Lu Xun breathed his last breath than the Chinese Communist Party began to build him into its own narrative of national revival, structured around the interpenetration of revolution and nationalism. Lu Xun's biography, which spanned the crucial juncture from late-imperial reformist gentry to nationalist revolution, the New Culture, and finally to the rise of communism as a response to many of the problems that had prevented China's full transformation into a modern democracy, began to serve as an explanatory model for the entire historical evolution of the first half of the twentieth century. The understanding of May Fourth in China today, at least outside academia, remains firmly anchored in the national narrative set out in the two CCP resolutions on Party history (1945 and 1981): the revolution is presented as a prerequisite for national revival, as also illustrated in the official blockbuster Beginning of the Great Revival (Jian dang wei ye, 2011). The New Culture movement is thus reduced to the "patriotic" demonstrations of 1919, blotting out the ideological diversity that blossomed from 1915, encompassing anarchism, liberalism, and localism. As is well known, this instrumentalisation of Lu Xun in the service of reducing the historical complexity of his time peaked during the merciless exploitation of his name and works during the Cultural Revolution.

The other, more substantive reason for Lu Xun's current relevance is that he confronted many of the dilemmas that China still faces today. Questions related to democracy, to Westernisation, and to the individual as the yardstick of a modern value system, have all been deferred rather than rendered obsolete by the historical events of the last 60 years. Lu Xun's reflections on these and other questions remain evocative to us because they are never ideological, but rather always seek to tease out the contradictions or tensions between different theories and approaches.

Leaving aside the debates over his work that took place during his lifetime, Lu Xun has gone through three main phases of reception over the three quarters of a century since his death in 1936, all of which remain alive today.

(1) The first phase consisted mainly of constructing what we may call the "official reading" of Lu Xun. Today, while he is no longer celebrated as the "commander in chief of [China's] Cultural Revolution," Lu Xun continues to be read and taught in China as a revolutionary fighter and patriot rather than as a complex writer of fiction and poetry, with an overemphasis on his political journalism of the 1930s rather than his fiction of the 1920s. In January 2012, for example, Peking University Professor Kong Qingdong 孔 慶東 referred to Lu Xun's denunciation of xizai 西崽 (Western fops) to justify his diatribe against Hongkongers' propensity to embrace Western-style rule of law and values, showing that this reading and its implied interpretation of the New Culture movement remain useful in China today.

(2) In a post-World War Two context in which Lu Xun had become canonised on the mainland while remaining banned in Taiwan, where he was la- belled a communist writer, the first alternative readings of Lu Xun, building on annotations and biographical writings by contemporaries such as Cao Juren 曹聚仁, who came to Hong Kong in 1950, began to emerge in Western academia in the 1960s. The Hsia brothers, in particular T. A. Hsia's 夏濟安 seminal The Gate of Darkness, first published in 1968, played a major role in unearthing the aestheticism in Lu Xun's works such as Wild Grass, as did the writing of Belgian sinologist Pierre Ryckmans (pen name Simon Leys). Leo Ou-fan Lee's 李歐梵 edited volume Lu Xun and his Legacy (1985) and his authoritative study Voices from the Iron House (1987) represent a culmination of scholarship undertaken in this perspective, in which psychological introspection, probing of gender roles, cosmopolitan connections, and nostalgia for vanishing local cultures take precedence over anti-colonialism and the celebration of left-wing martyrs. Theodore Huters and Marston Anderson's contributions, in a different but related vein, almost simultaneously underscored the specific importance of moral dilemmas in Lu Xun's aesthetics.

(3) In recent years, new readings of Lu Xun have emerged in China under the perspective of intellectual history. In the 1980s, pioneers such as Beijing Normal University professor Wang Furen 王富仁 (b. 1941) and Peking University professor Sun Yushi 孫玉石 (b. 1935) had revived the humanist Lu Xun against the Maoists, but their readings remained within the politically acceptable orbit of critical realism. After 1989, there was a marked search for a different Lu Xun and a return to his early writings. Scholars such as Peking University professor Qian Liqun 錢理群 (b. 1939) and Tsinghua Professor Wang Hui 汪暉 (b. 1959) searched for a new contemporary relevance, taking particular inspiration from readings developed by Japanese Marxist critics such as Takeuchi Yoshimi 竹内好 (1910-1977), who enjoyed an ongoing "fever" on the mainland from around 2000. (1) Younger scholars such as Kiyama Hideo 木山英雄 (b. 1934) played an important role in highlighting the importance of Zhang Binglin 章炳麟 (Zhang Taiyan, 18681936) and other heterodox thinkers in Lu Xun's intellectual world, thus grounding the critical momentum contained in his writing not only in aestheticism but also in a set of complex intellectual debates in Lu Xun's time. (2) The development of un-orthodox (in the Chinese context) Marxist readings of Lu Xun also reflects the need for a critical outlook in a society that has undergone extreme commodification: such read-

Some of the material presented here is taken from an unpublished paper, "Reinventing Lu Xun as a Patriot, an increasingly difficult task?", given at a conference entitled "Lu Xun \& his legacy" in New Delhi, 16-18 November 2012. I am also indebted to Prof. Sun Yu for comments on the current state of Luxunology.

1. For an overview see: Christian Uhl, "Displacing Japan:Takeuchi Yoshimi's Lu Xun in Light of Nishida's Philosophy - and vice versa," in Positions: East Asia Cultures Critique, Vol. 17, No. 1 (special issue on Philosophy and the Political in War-Time Japan, spring 2009), pp. 207-238. Viren Murthy, "Zhang Taiyan and Chinese Modernity," in The Political Philosophy of Zhang Taiyan, Leyden, Brill, 2011, pp. 1-49. See also: Maruyama Noboru, "Lu Xun in Japan," in Leo Ou-fan Lee (ed), Lu Xun and his Legacy, Berkeley, UC Press, 1985, p. 216-241.

2. See Hideo Kiyama, "The Literary Renaissance and the Literary Revolution," Acta Asiatica, Vol. 72, March 1997, pp. 27-60. 

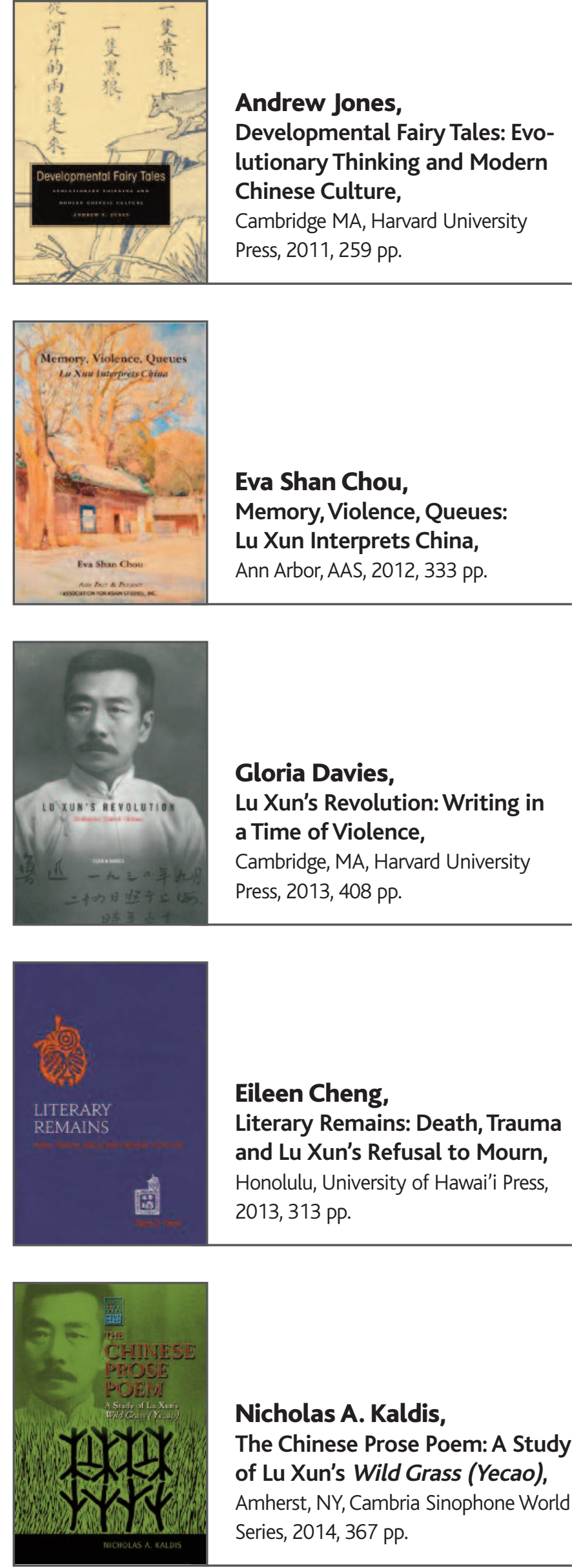

Nicholas A. Kaldis, The Chinese Prose Poem: A Study of Lu Xun's Wild Grass (Yecao), Amherst, NY, Cambria Sinophone World Series, 2014, 367 pp. ings of Lu Xun, understood as the most articulate critic of China's first modernity, with its ubiquitous economic exploitation and hijacking of the new polity by traditional authoritarian elites, has not only fuelled new-Left nostalgia for the revolution; it also serves to counteract the celebration of Chinese pride that has become the new national credo. Against this backdrop, the last three years have seen new English-language publications on Lu Xun, five of which will be discussed here. Each book is based on an original methodological approach, and taken together, they represent an important diversification of the approach to Lu Xun in Western academia. Although it is difficult to distinguish a single new trend, this paper will attempt to situate them within some of the debates in Chinese academia.

Andrew Jones' 2011 study Developmental Fairy Tales: Evolutionary Thinking and Modern Chinese Culture draws inspiration from the intellectual history approach, while closely connecting it with social history in a particularly stimulating way. Jones draws attention to the intimate connection between modern Chinese fiction and the discourse of development or evolution, predicated on the belief in progress and uniquely illustrated in the figure of the child (the growing child as a metaphor for the evolution of mankind). Lu Xun is depicted as a critic of evolutionism - a tenet of modernity in May Fourth times. As highlighted by James Reeve Pusey in an earlier study on the subject, there is at least a tension between the conception of evolution as biological law and "the difficult mission of pushing the developmental process forward, of enlightening the nation" as modern writers understood it (p. 10). For Jones, this dilemma defines a "crisis of agency" (p. 12) latent throughout Lu Xun's work and finding its most arresting image in the "frozen fire" of Wild Grass.

Two figures in particular are closely connected to the discourse of development: the child and the animal (representing different stages of development), which are recurrent throughout Lu Xun's writings. Through a series of close readings, innovatively connected with vernacular texts of social history, Jones explores various aspects of the tension between "historical necessity" and "historical agency" in Lu Xun's writing (p. 34). After an opening devoted to possible sources of the famous parable of the "sleepers in the iron house," the second chapter focuses on Lu Xun's story "Guduzhe" ("The Misanthrope." I find this well-established translation misleading, but Jones retains it while noting the alternative "The Loner"). Picking up the idea of "vernacular modernism" (p. 67), Jones reads "Guduzhe" against the rapid circulation of a vernacular version of evolutionary theory, resulting in the conflation of nations and species, national and evolutionary history. Children's magazines such as Commercial Press's Children's World (Ertong shijie) and Chunghwa's Little Friend (Xiao Pengyou), established in 1921, were prime vectors of the ideology of "educating" Chinese children "for upward mobility in the colonial world order" (p. 89). Against this background, "Guduzhe" takes on new meaning as a counter-discourse on heredity. For Jones, Wei Lianshu inherits the social isolation and loneliness experienced by his grandmother, which he bequeaths, though through no link of blood, to the narrator Shenfei. Jones reads this final twist as proof that Shenfei "refuses the imperatives of natural-historical narrative" (p. 98). On the contrary, he chooses to remain true to his friend's loneliness and moral rectitude and refuses the imperatives of "wealth and power." However the reader remains a bit frustrated that 
the conclusion of this chapter does not more effectively pull together the different strands it develops, in particular whether and how the "howl of the wolf" adopted by both Wei and Shenfei represents a form of evolutionary regression. ${ }^{(3)}$

The third chapter is devoted to representations of children in Republican print culture as a background to rereading "Diary of a Madman." Andrew Jones argues that the New Culture project "places the figure of the child and the practice of pedagogy at the centre of questions of national history" (p. 106). Jones reads the episode in which the madman realises that his brother has long been slipping human flesh into their meals as an image of the "terrifying and tainted inevitability of cultural inheritance" (p. 108) and of the "impossibility of a historical break with a tainted culture" (p. 111). Lu Xun thus takes issue with the May Fourth instrumentalisation of children (and even "consumption" for book-selling purposes). Similar to Lu Xun's brother Zhou Zuoren's call for a humanistic treatment of children (in a fascinating aside, Jones describes how Zhou, building on Herder and Fichte via Yanagita Kunio 柳田國男 as well as Ming iconoclasts such as Li Zhi 李䞇 and Feng Menglong 馮夢龍, conceives of the "child-heart" as a figure of authenticity), Lu Xun critiques the May Fourth "business of enlightenment" and its vast market of books for and about children, textbooks, and educational toys as a vector of bourgeois consumption and symbolic identification with Western modernity. Chapter 4 deals more precisely with the toy industry and Sun Yu's 孫瑜 1933 film Playthings - the story of a patriotic industrialist producing toys. Toys here come to be seen as educational/evolutionary tools, and their production becomes a metaphor for the "production" of Chinese children in a discourse that further marginalises people like the pauperised heroine of Sun Yu's film.

Chapter 5 begins with an essay by Lu Xun on Hagenbeck's circus, which reveals astonishing similarities to Kafka's "A Report to the Academy" (as noted by Jones in a footnote). With biting irony, Lu Xun critiques the training of animals, which becomes a metaphor for the entire mindset of evolutionary thinking. Jones connects this essay with Lu Xun's translation of Vassili Eroshenko's children's fairy tale "A Narrow Cage," the story of a tiger in a zoo who dreams of liberating mankind, which contains an implicit critique of enlightenment and ends in a final impasse. A full translation (based on Lu Xun's Chinese translation of Eroshenko's Japanese original) is included in an appendix.

This book undoubtedly opens new perspectives in taking Lu Xun out of the modernist "cage" by highlighting both his implicit and explicit critiques of the evolutionary discourse in its various forms, and his immersion within the world of vernacular discourses against which his writing makes sense. While this study broadly echoes Wang Hui's view of Lu Xun as a critic of modernity, on a methodological level, the connection between intellectual and social history (print culture) is particularly pleasing, although it would be nice if the author drew clearer conclusions at the end of each chapter, or at least at the end of the book (which stops almost as abruptly as Eroshenko's story).

$$
* * *
$$

Eva Shan Chou, in addition to her work on classical Chinese poetry, is well known to Lu Xun scholars for her ground-breaking article on the hesitant early reception of Lu Xun. ${ }^{(4)}$ Her new book is organised around the ambiguous relations between (iconoclastic) violence, (nostalgic) memory, and the way both of these feelings come together in Lu Xun's representation of queues, the symbol of Chinese submission to Manchu rule that concentrated the hostility of progressive thinkers in the late years of the Qing. Using a similar methodology to her earlier article, she approaches Lu Xun not through the broad-brushed characterisations of literary histories but by reinvestigating a series of small but concrete events and how they are dealt with in his writing, especially in some texts considered marginal such as his classical poems. Her view of the literary field is refreshingly post-bourdieusian: as she sets out in the first chapter, she considers Lu Xun in terms of his reception, influence, and social stature (using personal writings and historical material), debunking the literary myths of May Fourth and of Lu Xun as representative and speaker both for the Chinese nation and against the "national character" that he carefully constructed (his own rendering of his biography as "a recapitulation of China's recent history and identity," p. 28). However, at the same time she avoids reducing his writing to a simple quest for literary or moral prestige, as in certain overly sociological readings, and remains committed to textual analysis.

The following three chapters are all related to the queue as a symbol both of violence and memory, not a straightforward symbol of oppression, but the complex symbol of a whole generation (p. 40). This approach connects with the previously mentioned turn in Chinese scholarship to the "early Lu Xun." Chapter 2 investigates in great detail the historical and intellectual background of Lu Xun's poem "Zi ti xiao xiang" (Self-inscription on a small photograph), a stridently nationalistic quatrain using the vocabulary of Qu Yuan's 屈原 Elegies of Chu (Chuci 楚辭), originally inscribed on a 1903 photograph in military uniform taken just after Zhou Shuren 周樹人 (the future Lu Xun) had his queue cut off in Japan. Eva Chou convincingly underlines the banality of both the act and the poem: Zhou Shuren at this point was simply a typical Chinese student in Japan who deflated the meaning of his queue-cutting as simply for "convenience" while at the same time commemorating it with an inflated poem. This is supplemented by a wealth of historical contextualisation about student movements in Japan, the conclusion being that 1903 marked a high point in Lu Xun's nationalism, from which he later distanced himself, even critically highlighting that "What they called Revolution was in fact ethnic revolution" ("Various memories").

Chapter 3 offers a close reading of five Lu Xun texts written in 19201922 (including "Ah Q") and returns to the problem of the queue and violence. It would make a good reading assignment for a class on "Ah Q," again providing many historical details about the composition of the five texts and the historical events (in particular the Zhang Xun restoration of 1917) that triggered Lu Xun's renewed discussions of queues. While hairstyles again served as pretexts for violence in the early 1920s (in this case against women who bobbed their hair), in Chou's view, Lu Xun then still believed that literature was useful to fight this sort of violence. Chapter 4, by contrast, focuses on Lu Xun's increasing scepticism, crystallised this time in the events of February 1931, when the KMT executed the "five martyrs" (on February 7), (5)

3. If an autobiographical reading must be adopted for "Guduzhe," it may be more convincing to identify Wei Lianshu with Lu Xun's friend Fan Ainong and Lu Xun with Shenfei, as this is a pen name he himself used. See the discussion of Eileen Cheng's book below.

4. Eva Shan Chou, "Learning to Read Lu Xun, 1918-1923:The Emergence of a Readership," The China Quarterly, Vol. 172, 2002, pp. 1042-1064.

5. The "five martyrs" (Li Weisen, Hu Yepin, Rou Shi, Yin Fu, and Feng Keng) were young members of the League of Left-Wing Writers who were arrested and executed by the KMT for communist activities. 
triggering Lu Xun's rediscovery and new calligraphic rendering of his 1903 poem on Lunar New Year's Eve of 1931 (and once more in December 1932). This poem takes on new meaning in conjunction with Lu Xun's 1933 essay "Remembering in order to forget," which also contains an eight-line poem originally written on the evening he learned of the executions in 1931. A third classical-style poem, "To Mr O.E.", is also analysed in this connection. The chapter ends with a discussion of Lu Xun's two 1936 essays commemorating Zhang Binglin upon his death. Eva Chou here highlights the circular connections between several texts: Lu Xun quotes Zhang's own classical poems commemorating the anti-Manchu revolutionary Zou Rong 㱀容 (1885-1905), written in June 1903, just before Lu Xun's "Self-inscription," which Chou dates to July 1903. Finally, Chapter 5 provides some interesting discussions of Lu Xun's engagement with the woodcut genre, which in Chou's view marks his acquiescence to the redefinition of his public persona as a left-wing writer.

This study, which draws suggestive connections in a most original way between close readings of texts, politico-historical events, and the larger context of intellectual history, highlights Lu Xun's continued engagement with political violence and the ambiguous legacy of the lateQing revolutionary movement. It also effectively illustrates Lu Xun's interest in "small" rather than large issues of politics (cutting queues), and the importance of the late Qing intellectual context, and Zhang Binglin in particular, in shaping his worldview.

Gloria Davies' book Lu Xun's Revolution: Writing in a Time of Violence (2013) takes as its subject "the last phase of Lu Xun's career" (p. 5), spanning the years 1927-1936, when he was preoccupied with the idea of revolutionary literature, for which he harboured contradictory feelings. Contesting the idea that the late Lu Xun is atypical, Gloria Davies proposes to contextualise the "barbed essays" by providing more background on the debates of which they are part, underscoring that Lu Xun has suffered from the fading out of his opponents. However, the central thread of her argument is really about language and the struggle between the vernacular (baihua) and classical Chinese (wenyan): reaffirming Lu Xun's position as a humanist, in continuity with Chinese critics such as Qian Liqun, she underlines his continued will "to claim the destruction of wenyan as his guiding purpose," although he never wrote entirely in baihua (p. 16).

Chapter 1 provides a considerable amount of historical background and situates Lu Xun as a humanist. Discussing the break between the KMT and CCP, which Lu Xun witnessed in Guangzhou in 1927, Davies quotes the poem "The Shadow's farewell," which she reads as "an appeal for fidelity to one's conscience and critical judgment. It offers a way of affirming the cause of revolution but without endorsing the false prescience of a final destination" (pp. 42-43). Chapters 2 to 4 focus on the factional battles among the intelligentsia in Shanghai from the late 1920s. In Chapter 2, Lu Xun's spats with the Crescent Moon (Xinyue she 新月社) literary society (in particular Chen Yuan 陳源, editor of Xiandai pinglun), allegorised in his essay on Weijin writers, are traced back to their origins in 1925. While Xu Zhimo 徐志摩 and the Crescentists openly championed the market and Shanghai's print capitalism as guarantees of intellectual freedom (p. 107), Lu Xun criticised them for their "compradorial anxiety to secure foreign patents" (p. 108) and went to great pains to highlight his own integrity, which Davies interestingly contextualises through a well-documented overview of the typical incomes and lifestyles of Lu Xun and other writers. In Chapter 3, Davies argues that far from taking a "Marxist turn," Lu Xun became increasingly critical of revolutionary doctrine after 1927, in particular because of its growing estrangement from baihua. She documents Lu Xun's quarrels with two younger disciples: Sun Fuyuan 孫伏園 (who published the journal Threads of thought / Yusi) and Li Xiaofeng 李小峰 (because of an essay he wrote about Lu Xun without consulting him). Davies gives interesting arguments about Lu Xun's "indifference to Marxism as a system or a science" and explains his Marxist turn as "more a radicalization of his humanistic disposition than a conversion to Marxist theory" (pp. 160-161), a position close to contemporary Chinese liberals. Chapter 4 deals with Lu Xun's stormy relations with the Left, beginning with the polemics of 1928 with the Creation Society (Chuangzao she 創造社), during which Lu Xun was "pronounced a fascist who called for the murder of young people" by one Du Quan, most probably a penname for Guo Moruo 郭沫若, and was called "outdated" by Qian Xingcun 錢杏邨. Quoting Wang Furen, Davies highlights Lu Xun's endorsement of ren 仁, benevolence and humanity.

The book's greatest contribution is undoubtedly in Chapter 5, devoted to the prose poems of Wild Grass. Davies begins by reminding us that the collection was instrumental for critics such as Qian Liqun and Sun Yushi in trying to reclaim Lu Xun from Maoist philosophy in the 1980s by emphasising the book's individualistic "philosophy of life." As a book of lyrical poetry in which revolutionary and social themes may seem secondary, it had been left largely untouched during the Maoist era. For Davies, however, it is first and foremost a work about language: Lu Xun's "poetic expressions of faith in the emancipatory potential of baihua, envisaged and defended as an egalitarian panChinese language in the making" (p. 230). "If he disavowed wenyan as utterly corrupted by the hierarchism of dynastic culture, he was even more averse to the idea of baihua's being put in the service of what he regarded as empty universalisms" (p. 233). The two figures in "atrophied confrontation" in "Revenge I" are read as a symbol of the "timeless facing-off" between wenyan and baihua in Lu Xun's own works, paralysed in an irresolvable stand-off. In the preface to Wild Grass, wenyan is revealed as the soil from which the wild grass of baihua has grown, a soil the author says he detests. Baihua is further presented as "a 'weapon' for cutting down elitist sophistry." The journey to the west of the "Wayfarer," who gives his name to a long dramatic poem in the collection, is read as an uncertain quest to escape from wenyan, although whether this really echoes Heidegger's "notion of language as a journey without end" (p. 260) remains doubtful; indeed Davies herself ends up explicitly undermining this comparison by characterizing Wild Grass as "a poetic celebration of baihua, aimed at nurturing a language of common belonging into being," far from Heidegger's linguistic essentialism.

Chapter 6 deals with Lu Xun's wholesale indictment of "Chinese writing as a foundational injustice" (p. 283), "a 'document of barbarism' masquerading as a 'document of culture'" (p. 283), as Gloria Davies aptly puts it, borrowing Benjamin's words. She goes on to quote the image of the "gate of darkness" in the preface to Nahan, compared by T. A. Hsia to the mythical Herculean figure of Xiong Kuohai from the Shuo Tang, holding up the city gates of Yangzhou to allow his friends to escape. For Davies, the "thousand pound gate" held up by Lu Xun is once again the gate of wenyan. In his "ghost stories" about Wuchang and Nüdiao, Lu Xun dwells on "afterlife as the sole prospect of justice for the oppressed" (p. 302). Davies ends with a rich overview of debates about Lu Xun in the 1980s and 1990s, including recent essays by Kong Qingdong, Han Han 韓寒, and Zhang Chengzhi 張承 志. She concludes that "Lu Xun's revolution consisted in making war against rote-learned habits of language and opposing the ruling class's monopoly 
of written Chinese. He found the radical egalitarianism that Communism promised deeply appealing. Hence while he abhorred the repressive politics of both the left and the right, he sought to defend the left as offering the best hope of a just society of fellow humans" (p. 331). For Davies, this position of "cultivating empathy through literature but [maintaining] a highly circumspect attitude to the vanguard role of the left" is best expressed in Lu Xun's linguistic commitment: "He believed he was defending baihua as a vehicle for human feeling" (p. 331).

One shortcoming of the book is that the chronology can be quite confusing (e.g., in the discussion on guocui p. 126). While Gloria Davies sets out to focus on the post-1927 Lu Xun, the book in fact repeatedly undertakes long digressions into his pre-1927 writing. In fact, the first three chapters never really move beyond 1927, the supposed starting point of the book, and frequently use flashbacks to various moments in the 1910s and 1920s. The greater insights may not so much lie in the contextualisation of Lu Xun's javelin essays - although the author has clearly undertaken some painstaking philological work - but rather in the repositioning of language as Lu Xun's central concern, and an original rereading of Wild Grass as an allegory of the struggle between baihua and wenyan. In this respect, many questions remain open. In Chapter 5, Davies singles out "authenticity," defined as "a general moral principle" and "honest communication," as Lu Xun's strongest linguistic commitment (pp. 232-33), yet such a conclusion seems both a bit underwhelming and also overly faithful to traditional aesthetics ("shi yan zhi" 詩言志 or "poetry expresses intention"). Davies similarly writes: "In contrast to his Marxist lexicon, Lu Xun dwelt on empathy and honesty as the indispensable virtues for promoting an egalitarian humanism in China" (p. 267). In fact, as shown in the readings of Wild Grass, the whole problem is that baihua and wenyan cannot be neatly split along the lines of moral authenticity (when he criticises baihua as a vehicle for Marxist abstractions) - and this is precisely what makes his writing so interesting.

Eileen Cheng's study presents a comprehensive overview of Lu Xun's "creative" writing, encompassing his two collections of fiction, Wild Grass, his late collection Old Stories Retold, and childhood reminiscence pieces collected in Dawn Blossoms Picked at Dusk. It is structured around the question of Lu Xun's engagement with traditional form and content in his work, raising the issue of a culture coming to terms with its past, and providing forceful evidence for the importance of understanding Lu Xun in the context of both traditional and modern forms. It represents a timely synthesis on the question of Lu Xun's use of traditional forms and sources.

Part 1 probes Lu Xun's rethinking of the past in his fiction, most prominently using the trope of cannibalism ("Diary of a Madman"). Quoting the idea that Lu Xun writes "fictions of atonement" (to atone for literature's failure to deal ethically with the suffering of others, an idea within the general orbit of Ted Huters' and Marston Anderson's approach), Cheng highlights that Lu Xun, when paying homage to forgotten victims in general, rejects "mourning" and the reconstitution of a community that it would imply. Wading through a jungle of existing scholarship, Cheng brings original textual insights to the canonical "Diary of a Madman": she suggests that the eponymous character resembles a kaozheng 考證 (evidential) scholar who uses textual material to refute common readings of the classics, rather than an iconoclast, just as the preface displays certain similarities with the postface of Sima Qian's Records of the Grand Historian. Sima Qian is also the first in a line of figures described by Cheng as "a tradition of marginalized scholars" (p. 59), commemorated by Lu Xun in his essay on his friend Fan Ainong 范愛農 and the story "The Misanthrope," which she reads as a fictionalisation of Fan's biography. In it, the relation between Shenfei and Wei Lianshu parallels that between Lu Xun and Fan, with Wei's refusal to mourn his grandmother echoing Fan's refusal to mourn the executed revolutionaries Xu Xilin 徐錫麟 (1873-1907) and Qiu Jin 秋瑾 (1875-1907) when news of their death reaches Japan. Cheng concludes that Lu Xun's vision of history is a cyclical one in which "persecution of the marginalized and the vacuous rituals mourning them will continue" (p. 71).

Part 2 deals with Lu Xun's disappointment in and growing estrangement from the practice of New Culture and its increasing commercialism (print, film, and entertainment culture). Cheng notes his hostility to spectacles and exploitative images of women circulated in the new popular culture, and his debunking of new culture intellectuals' fascination for "liberated women" as a new form of male hypocrisy. She concludes that he may have retained sympathy for a "traditional view of gender" precluding female agency, though this idea seems to be contradicted by some of the examples Cheng herself provides: Lu Xun's endorsement of his killed student Liu Hezhen 劉 和珍 can hardly be ascribed only to her "smile and pleasant manner" (p. 100). Romantic love is debunked as a new form of hierarchy and male manipulation in "Regrets" ("Shangshi," 1925); to this, Cheng adds the insightful observation that the diary form in this story is no longer a tool of enlightenment as in "Diary of a Madman" seven years earlier, but has become a tool of "self-deception" by the New Culture male intellectual, perhaps reflecting Lu Xun's growing loss of faith in the New Culture movement. Finally Cheng devotes one chapter to exploring the theme of nostalgia in Lu Xun's "hometown fiction." While Lu Xun was critical of the propensity to idealise the native place and consequently painted "a dismal picture of village life," he occasionally alludes to the rural utopias of classical literature, as at the end of "Hometown" ("Guxiang"). Cheng provides several sources for the metaphor of the path at the end of this famous story, suggesting the relevance of a passage in Mencius and another one in Zhuangzi's Qiwulun. Despite the political difficulties it raises, Cheng interprets nostalgia as a form of meaning: "dwelling on loss was a means of recovering meaning from the violence that is history" (p. 166).

The "carnival element" of folk culture features prominently in the third section of Cheng's study, which highlights Lu Xun's "sustained interest in the mythical, the spiritual, the otherworldly," all described as experiences of "enchantment" (p. 192). Through detailed readings of Old Stories Retold, she shows how Lu Xun came to see the New Culture movement as a typical young literati endeavour to redefine hierarchy in their favour. In particular, the reading of "Resurrecting the Dead" suggests that elite culture remains dominated by "hypocritical scholars" in contrast with folk culture as a source of genuine "enchantment." Cheng concludes that the stories in this collection "show how fragments of traditional styles, forms and conventions could be recontextualised as a critical register to reveal unseemly truths about elite culture and the act of writing itself" (p. 218). In the epilogue, devoted to Wild Grass, Lu Xun's use of the past is compared to Benjamin's "utopian form of hope," in which the past can one day be resurrected to illuminate the present and the future.

Eileen Cheng's greatest contribution is no doubt in providing the most comprehensive and up-to-date overview in English of Lu Xun's fictional and narrative writings, which can easily serve as a guidebook to be read alongside the primary texts in a university course or by the general reader. Her central argument, about the importance of the past and tradition in Lu Xun's 
intellectual and formal development, is perhaps not entirely new, but is textually documented in a more systematic and rigorous way than previously. $* * *$

Nicholas Kaldis has published the first book-length study in English of Lu Xun's collection of prose poetry Wild Grass, entitled The Chinese Prose Poem (2014), underscoring the central place this text seems to be taking in the most recent scholarship. The structure of his book is original, with three introductory chapters providing the backdrop for a poem-by-poem study that makes up its bulk. In the first chapter, revisiting the preface to Nahan, Kaldis adopts a psychoanalytical framework drawing on Freud's concept of "abreaction" (p. 23) and referring occasionally to Kristeva and Lacan to describe Lu Xun's persistent return to and reconfiguration of moments of trauma. He also builds on Leo Ou-fan Lee's early interest in psychoanalytical readings of the collection. This is combined with an exploration of what he calls Lu Xun's "Nietzschean-existentialist worldview" (p. 32) discussed in Chapter 2. Of course the influence of Nietzsche on Lu Xun, though long denied by mainland orthodoxy, is now well known and accepted; on the other hand, the retrospective use of the "existentialist" label seems less convincing, although Kaldis dutifully points out the difficulties in applying it to works that predate the term (p. 64). Lu Xun's critique of ideological discourses and isms, wariness of both tradition and future utopias, and practice of "ruthless self-scrutiny" (p. 73) as an antidote to cooptation and misreading of his own work all chime with Nietzsche's worldview and practice, although the argument may seem overly systematic when it is suggested that Nietzschean self-doubt is what made Lu Xun wary of ideologies until his death (p. 77). Chapter 3 brings a welcome comparative contextualisation of the prose poem form and provides a complete overview of the form's history in China, identifying the fu 賦 poem as a possible pre-modern precedent and inspiration. The influence of Turgenev and Baudelaire on Lu Xun's prose poems is discussed: while Kaldis rejects Sun Yushi's argument about the importance of Turgenev, he also finds less proof documenting Baudelaire's influence than one might have anticipated.

Chapter 4 is composed of close readings of the 23 poems of Wild Grass. Nick Kaldis argues for adopting a reading framework inspired by Walter Davis, in which "representation is cognition" (p. 146), and consequently reads the poems as "attempts to engage and capture in language and image the inner world of the subject (the psyche) in its dynamic interaction with the outside world (the historical context)" (p. 146). Poems such as "The Shadow's Leave-Taking" or "The Passer-By" serve as examples of the conflict between id and superego that structure the collection - the latter being read as the exemplification of "Lu Xun's struggle to simultaneously follow both the tortuous inner road of sustained ruthless introspection and outer road of cultural iconoclasm" (p. 209). Questions of gender and sexuality feature prominently in "The Passer-By," "Tremors of Degradation," and several other commentaries: "Revenge I" is thus read as a visual confrontation in which both genders are incapable of accepting otherness. ${ }^{(6)}$ The Christ figure in "Revenge II" is effectively tied in with Ah Q; however, precisely because of this similarity I cannot agree that Nietzsche's critique of Christianity is of "infrequent concern to Lu Xun" (p. 183): it is precisely this critique of Christianity that Lu Xun translates into his own critique of the weakness of Confucianism. This discussion reads well alongside Kaldis' analysis of "Amid Pale Bloodstains," where Zhuangzi is identified as the source for the image of a "cruel and capricious creator" - Lu Xun is shown to be critiquing the acceptance of such cruelty in Daoism. Kaldis effectively highlights the importance of the seven "dream poems" at the centre of the collection: the reading of "Dead Fire" is particularly effective in tying together psychological and political aspects, highlighting that the flame ends up "taking up agency" for itself (it decides to escape from Hell) and thus escapes certain extinction, while the more carefully calculating narrator is crushed by a chariot. This again ties in with the "epiphany" of a "fierce warrior" in what is identified as a Nietzschean assertion of agency in "Amid Pale Bloodstains" (p. 261).

One quibble is that there are sometimes too many digressions that tend to drown out the main argument. It is also regrettable that the author does not take the time to tie together the various threads discussed in the close readings - the conclusion is only a half a page long. Readings could draw on a greater diversity of interpretations: in particular Buddhist allusions are mainly confined to the footnotes. While there is nothing wrong with the reading of "A Wise Man, a Fool and a Slave," referencing Takeuchi Yoshimi's influential interpretation of this poem as the basis for his own critique of Japan's "slavish" imitation of Western colonial modernity and endorsement of Lu Xun as a possible foundation for an "Asian modernity" might be more relevant than referring to Althusser (p. 251). In his 1948 essay "What is modernity? (The case of China and Japan)" (Kindai to ha nanika), Takeuchi highlights how the man who tries to help the slave by breaking down a wall in his house to create a window will be denounced and driven off by the slave himself, who is subsequently rewarded by his master. As Takeuchi writes, "The 'most painful thing in life,' awakening from a dream, occurs when the slave rejects his status as slave while at the same time rejecting the fantasy of liberation, so that he becomes a slave who realizes he is a slave. [...] This is the meaning of despair found in Lu Xun." (7) Takeuchi interprets this brief and enigmatic text as a parable of Japan's and Asia's modernisation, arguing that Japan represents the slave who becomes the master's master, a coloniser to counteract colonisation. ${ }^{\left({ }^{8}\right)}$ Takeuchi's reading is particularly interesting because it became influential in China in recent years: its implicit critique of the modernisation paradigm has been used to question Lu Xun's status as a proponent of Enlightenment, in particular by scholars critical of China's turn to crony capitalism from the 1990s onward. In particular, as Takeuchi is not yet well known to Western scholars, it would be useful to discuss him more. However, apart from such details, Kaldis provides a welcome overview of this crucial collection as well as offering psychoanalysis as an alternative theoretical framework to the linguistic reading developed by Gloria Davies. $* * *$

In sum, these five publications on Lu Xun express, to varying degrees, the writer's doubts about modernity (evolutionism, violence, queue-cutting) as well as about tradition. Lu Xun remains a "homeless" author whose critics are scattered around the world: his reception in any one country or region suffers from too many shortcomings to be considered authoritative. (9) Many of the studies give a central position to Wild Grass, an emblematic work of the more ambiguous Lu Xun. ${ }^{(10)}$ Several of the books underscore the dual

6. This may seem a bit ironic given that the genders of the protagonists are not specified in the poem itself.

7. Takeuchi Yoshimi, "What is modernity? (The Case of China and Japan)," in What is Modernity, trans. Richard Calichman, New York, Columbia University Press, 2005, p. 71.

8. This was a contradiction Takeuchi knew well, having himself fought in the imperial army in China and welcomed the bombing of Pearl Harbor in a fiery speech announcing the end of Western domination.

9. This point is amusingly illustrated by the fact that there is currently no edition of reference that can be considered authoritative: the mainland versions use simplified characters and still suffer from certain ideological interpretations in the paratext, and traditional character versions in Taiwan and Hong Kong often simply reprint the mainland edition, converting characters "back" to traditional, whereas Lu Xun sometimes originally used variants.

10. See also the special issue of the Journal of Modern Literature in Chinese (Vol. 11.2, Spring 2014) entitled "Layers of the Real: Lu Xun's Wild Grass," guest edited by Nick Admussen, with contributions by Roy Chan, Charles Laughlin, Mabel Lee, and Nick Admussen. 
nature of his work: Gloria Davies by highlighting the battle between wenyan and baihua, Eva Chou and Eileen Cheng by documenting the importance of traditional forms and references in his writing. Davies' argument seems to contain an element of tension or contradiction between her insistence on Lu Xun's humanism and his attachment to "authenticity" as a criterion of literature on one hand, and her designation of language as the central problem of his work on the other: if the re-evaluation of the place of language is taken systematically, humanism guaranteed by a form of moral "authenticity" cannot be the ultimate criterion of literary creation in the sense that language can never unproblematically express the purity of moral intentions.

The expression of deep-set doubts about how to deal with the "slavishness" of the proletariat or of the subjects of a fallen empire that is struggling to become a Republic is most germane to Lu Xun's story "Ah Q." While Fredric Jameson and other scholars such as Lydia Liu have recently given new currency to the idea that Lu Xun in fact penned a critique of "national character," something uniquely Chinese that he saw as the main obstacle to China's modernisation, as noted previously, Lu Xun's critique of Confucian "slavishness" can be seen as a "translation" into the Chinese context of Nietzsche's critique of Christianity, which in this sense is not culturally specific. (11) To this we may add Takeuchi's reading, according to which the discourse of nation-building and self-strengthening as practiced by Japan in the interwar period was an example of the slave trying to enslave the master and thus reproducing the same relation of domination and exploitation on another level.

The dual nature of Lu Xun also continues to structure Chinese scholarship on Lu Xun, divided between traditional approaches that see him as a proponent of Enlightenment and progress and the readings that emerged from the 1980s calling into question his identification with modernity, or even describing him as a critic of modernity. This division is compounded by another, more political one between "liberals," who usually espouse the humanist readings, and the "New Left," which uses Lu Xun to critique capitalism, modernity, and enlightenment. Eileen Cheng and Eva Chou are particularly well-read in the most recent Chinese secondary literature, and their bibliographies are a useful resource. However none of the studies substantially discusses this central divide in Chinese Lu Xun research and its meaning, although most of them widely quote Wang Hui.

Wang Hui occupies a central position in this debate as the new generation's most prolific and original Lu Xun scholar but also a public intellectual who, since his dismissal from the editorship of Dushu in 2007, has moved closer to the New Left. He continues to intervene in the public debate both in China and through regular English translations of his work. He was the first to question the figure of Lu Xun as a humanitarian realist in the late 1980s, and to turn to Wild Grass and the early Lu Xun for evidence, two inflexions that continue to prove seminal in the works discussed above. Wang's latest contribution to the discussion, first written a few years ago and published in an English translation by Theodore Huters and Yangyang Zong in the journal Boundary 2 in 2011, (12) deals with Lu Xun's early and linguistically challenging text "A Refutation of Malevolent Voices" ("Po e'sheng lun"), written in 1908 while Lu Xun was in Japan and under the influence of Zhang Binglin's nativism, an influence reflected in the archaic language he chooses for his essay. This essay illustrates the previously mentioned important trend in Chinese Lu Xun research after 1989 (a unique crisis of faith in enlightenment) to turn to the "early Lu Xun" (zaoqi Lu Xun), a figure torn between different sets of ideas, references, and loyalties. Wang's essay therefore represents a useful complement to the studies discussed above, and deserves to be included in the discussion.

In it, Wang Hui highlights Lu Xun's critique of the anarchists' endorsement of cosmopolitanism in promoting Esperanto as a world language to solve the problem of communication. For him, Lu Xun's use of archaic pre-Song language represents an endorsement of Zhang Binglin's views on the importance of philology to reconstruct a heterodox indigenous tradition (Wang Hui stresses that for Lu Xun the archaic prose was the colloquial language of the ancients, which tallies with Gloria Davies' argument). Lu Xun's critique of cosmopolitanism is for him rooted in a rejection of Esperanto as a universal language, his reaffirmation of national sovereignty, and his critique of the anarchists' endorsement of the datong 大同 ideal, previously promoted by Kang Youwei 康有為, which Wang Hui denounces as founded on a form of racial hierarchy.

Wang Hui explicates Lu Xun's critique of Enlightenment modernity on three levels: a critique of the citizen ("doing one's duty"), a critique of the eradication of superstition, and a critique of the worship of aggression.

(1) Against the logic of the citizen, Lu Xun reaffirms the "voices of the heart," the affirmation of an inner spirit that will allow the "self" to achieve a public awakening. The awakening of the "voices of the heart" does not, however, awaken people as citizens or as cosmopolitans, but as "authentic" (once again a problematic term here in my opinion) and self-sovereign individuals (zhen 朕; "I"), through self-creation and self-expression (p. 90). Wang Hui associates these "voices of the heart" (xinsheng 心聲) with the romantic preference for ethnicity and the nation, but it is clear that they are profoundly moral in nature: revolution depends on interiority to produce a self-enlightened qun 群 (collective) where each individual realises his or her own identity. Wang Hui links this view with Zhang Binglin's rejection of Esperanto as an alienated language and his belief that political equality could only be achieved through difference, subjectivity, and respect for uniqueness, rebutting the worldview based on a universalising negation of difference. Somewhat like Davies, Wang Hui reads Lu Xun as a proponent of an oral language steeped in cultural authenticity; unlike her, he does not see him as a humanist.

(2) Rejecting the critique of superstition: Lu Xun takes a stance against this central tenet of Enlightenment, asserting that "the urgent task before us today is to rid ourselves of the hypocritical gentry; 'superstition' itself may remain" (p. 104). Lu Xun defines superstition as the product of a need of human beings for metaphysical belief, a definition Wang Hui notes is a pure product of modern thought. Again, Lu Xun opposes both Kang Youwei's agenda of reviving Confucianism as the official religion of a modern nationstate, and the anti-Manchu revolutionaries who revered the Yellow Emperor as a symbol of ethnic nationalism. Lu Xun highlights that the "hypocritical gentry" has, throughout China's imperial history, always advocated gongli 公理 or universal principles, while the religion embedded in ordinary people's lives was a constant source of creation and self-fulfilment, a position that resonates with Lu Xun's critique of science as a form of modern religion (Haeckel). Like Eileen Cheng, Wang Hui connects this with Lu Xun's lifelong interest in ghosts and spirits.

(3) In laying out Lu Xun's critique of aggression and "animalistic patriotism," Wang's reading is influenced by Takeuchi, who may well have originally

11. I have discussed this in Sebastian Veg, "Democratic Modernism: Rethinking the politics of early twentieth century fiction in China and Europe," Boundary 2, 2011, Vol. 38, No. 3, pp. 27-65.

12. Wang Hui, "The Voices of Good and Evil: What is Enlightenment? Rereading Lu Xun's 'Toward a Refutation of Malevolent Voices'," Boundary 2, 2011, Vol. 38, No. 2, pp. 67-122. 
read the corresponding passage of Lu Xun's text in which he denounces nationalism as a form of servility. Wang Hui stresses that Lu Xun's critique of nationalism is directed less against states than against individuals and their aggressive instincts, contrary to the anarchists. Lu Xun opposes nationalism in any other than a defensive function, seeing nationalists in dominated countries as slaves to the second degree, quoting the absurd pride some Chinese took in Wilhem II's "yellow peril" speech. Hence Wang's conclusion that Lu Xun is a "protector of national culture who opposes nationalism" (p. 123). We may note in passing that this position is not dissimilar to Chen Duxiu's early rejection of nationalism or jingoism. (13)

This article, especially read in conjunction with Eva Chou's reflections on nationalism and Gloria Davies' probing of authenticity, highlights the importance of Zhang Binglin and heterodox, "small" traditions inspired by local folklore and language in which Lu Xun saw the potential to break away from oppressive Confucianism. Here, perhaps, also lies an opportunity to define more rigorously "authenticity," which Gloria Davies refers to without providing a Chinese source or equivalent. As noted above, Andrew Jones refers to Zhou Zuoren's growing engagement with an "indigenous lineage" in which "the 'child-heart' (tongxin 童心) is privileged as a figure of 'authenticity' (as opposed to stale Confucian orthodoxy) of vernacular song and storytelling" (p. 118).(14) This idea can be connected to Wang Hui's reference to "voices of the heart" (xinsheng) as a criterion of "authenticity," a notion that, like the "mind-heart" (xin), is both moral and epistemological, referring to both a purity of intention and a sense of single cultural belonging in the Romantic vein. Hence, Lu Xun's understanding of democracy may be a more endogenous one than previously suspected, influenced not only by Western philosophy, but more importantly focusing on the village community and local culture as a potential arena to realise equality. In this respect, it is striking to note that non-hierarchical, i.e., democratic forms of social organisation in Lu Xun's stories are always connected to the context of locality: the narrator's mother's village in "Village
Opera," where women are not subjected to Confucian laws, and more generally the world of childhood, in which individuals are not separated by social hierarchies. In this sense one might argue that Lu Xun's endorsement of democracy in later years does not cancel out his earlier interest in heterodoxy and guoxue. It does, however, qualify Wang Hui's assertion that Lu Xun's critique of nationalism is still nationalistic because it is in the orbit of guoxue (p. 82). It might be more exact to say that Lu Xun has attempted in a sense to take the guo out of guoxue and to render the heterodox, local traditions that give its flavour to traditional Chinese culture, under the hue of a democratic form of social organisation, based on an anthropological, non-normative approach that does not consider village culture "backward." In this sense, the local, as a place where protodemocratic forms exist in the pre-modern context, may also be seen as a new horizon for Lu Xun studies.

These five English-language contributions open new avenues of exploration for future Lu Xun scholars. Lu Xun's engagement with vernacular culture is an important point shared by almost all scholars, be it in the form of the new vernacular print culture or woodblock art, or of Zhang Binglin's legacy of grounding the critique of Confucian tradition and hierarchy in the heterodox elements of village culture, or of his fight for a truly vernacular language. Therefore, while official curricula and propaganda organs have begun to loose interest in him, as attested by the removal of several wellknown texts from secondary school curricula ("Ah Q" was removed from the main section of Beijing literature manuals in 2007), or his surprising absence from the propaganda blockbuster Beginning of the Great Revival in 2011, the political questions that Lu Xun's writings raise remain as relevant to Chinese society as they were 80 years ago.

ISebastian Veg is researcher and director of the CEFC. CEFC, 20/F Wanchai Central Building, 89 Lockhart Road, Wanchai, Hong Kong (sveg@cefc.com.hk).

13. See Chen Duxiu, "Aiguo xin yu zijue xin" (Patriotism and self-awareness), Jiayin zazhi, Vol. 1, No. 4, 10 November 1914. See also Xu jilin's comment in his essay in the China Heritage Quarterly www.chinaheritagequarterly.org/features.php? searchterm=017_mayfourthmemories.inc\&issue= 017 and the comment by Xu Zhiyuan quoted in G. Barmé's editorial: www.chinaheritagequarterly.org/editorial.php?issue $=018$.

14. As noted by Jones, this idea is probably inspired by Li Zhi, who defines tongxin (child-heart) as zhenxin (true-heart or "authenticity") in the Tongxin shuo. Thanks to Yinde Zhang for pointing out this problem and providing the source. 